\title{
ABSTRACTS OF COMMUNICATIONS Proceedings of the Thirtieth Meeting of the Agricultural Research Modellers' Group
}

\author{
EDITED BY \\ J. FRANCE \\ The University of Reading, Department of Agriculture, Earley Gate, Reading RG6 6AT, UK
}

This group, which is concerned with the applications of mathematics to agricultural science, was formed in 1970 and has since met at approximately yearly intervals in London for one-day meetings. The thirtieth meeting of the group, chaired by G. J. S. Ross of the Institute of Arable Crops Research, Rothamsted, was held in the Wellcome Meeting Room at the Royal Society, 6 Carlton House Terrace, London on Friday, 3 April 1998, when the following papers were read.

Is there chaos in solute transport modelling? T. M. ADDISCOTT AND N. A. MIRZA. IACR-Rothamsted, Harpenden, Herts AL5 2JQ, UK

Chaotic dynamics is a consequence of mathematics itself and can appear in many physical systems (Rasband 1990). It involves deterministic, rather than random, behaviour, with the current state of the system depending unequivocally on the previous state. Chaos always arises from non-linearity in the system, but this is not the only contributory factor. The system has also to have more than one degree of freedom, that is, be non-autonomous. A feed-back loop is a common cause of chaotic behaviour. A wellknown example of chaotic behaviour is the simple logistic equation often used in population studies; here the feed-back arises from the dependance of $x_{n}$ on $x_{n-1}$. This function, like most chaotic systems, behaves chaotically only within a certain range. One of the hallmarks of chaotic behaviour is sensitive dependance on initial conditions (Rasband 1990). Many models for transport processes in soil, notably those based on the classical approach using the Richards Equation and the Convection-Dispersion Equation, are non-linear. The classical approach and the simpler SLIM leaching model (Addiscott \& Whitmore 1991) were therefore investigated for chaotic behaviour by testing their sensitivity to small changes in initial conditions. The SLIM model, which is not strongly non-linear, did not behave chaotically. We were also not able to induce chaotic behaviour in the classical approach, partly because we could not find a formulation that allowed us to vary the initial conditions as we wished, and also perhaps because we did not find the range in which chaos occurred.
Rasband, S. N. (1990). Chaotic Dynamics of Nonlinear Systems. New York: John Wiley \& Sons.

Addiscott, T. M. \& Whitmore, A. P. (1991). Simulation of solute leaching in soils of differing permeabilities. Soil Use and Management 7, 94-102.

A modification of a plant growth and competition model to allow for drought. L. R. BENJAMIN. Horticulture Research International, Wellesbourne, Warwick CV35 9EF, UK

Aikman \& Benjamin (1994) developed a model to simulate individual plant growth and the effects of competition between plants for growth resources. Although their model had a general framework to allow for many limiting resources, the model was calibrated for only light, temperature and carbon dioxide. Their model considered that environmental factors have a combined effect on plant growth analogous to Ohm's Law. To extend the model to allow for limiting soil water, a cabbage and an onion experiment were conducted. In each experiment, mixed-aged stands were established in well watered or drought conditions. A simple modification of the model to allow for soil water potential estimated at $20 \mathrm{~cm}$ depth gave a good fit to the data. Hence, assuming that only light and water stress limit growth, then relative growth rate is given by:

$$
\frac{1}{w} \frac{d w}{d t}=\frac{1}{\frac{1}{b \cdot \phi \cdot I}+\frac{1}{\Omega \cdot / \psi^{\theta}}}
$$

where $I$ is the total daily solar light integral, $\phi$ is a term for self-shading, which is dependent on plant 
weight and presence of neighbours, $\psi$ is soil water potential, and $b, \Omega$ and $\theta$ are constants.

Hence, in the equation above, the impact of soil water potential on plant growth is independent of plant weight. The pattern of weight changes in response to reduced soil water content were similar to those observed experimentally. This suggests that plants do not compete for soil water per se, but limited soil water supply acts to limit the growth of all plants. Hence, in these experiments the effects of soil water on plant competition can be likened to that of temperature. For both sizes of plants in both experiments the bulk of the soil water loss occurred from the top $50 \mathrm{~cm}$ of soil, with very little occurring from deeper in the soil profile.

The UK Ministry of Agriculture, Fisheries and Food funded this work.

Aikman, D. P. \& Benjamin, L. R. (1994). A model for plant and crop growth, allowing for competition for light by the use of potential and restricted projected crown zone areas. Annals of Botany 73, 185-194.

The use of steady state isotope dilution models for analysing leucine uptake by the liver and mammary gland of the lactating dairy cow. L. A. CROMPTON $^{1}$, J. FRANCE ${ }^{1}$, M. D. HANIGAN ${ }^{2}$, C. K. REYNOLDS $^{1}$, J. DIJKSTRA ${ }^{3}$, J. A. MAAS ${ }^{1}$, B. J. BEQUETTE ${ }^{4}$ J. C. MACRAE ${ }^{4}$ AND D. E. $\mathrm{BEEVER}^{1} .{ }^{1}$ The University of Reading, Department of Agriculture, Earley Gate, PO Box 236, Reading RG6 6AT, UK, ${ }^{2}$ Purina Mills Inc., PO Box 66812, St.Louis, MO 63166-6812, USA, ${ }^{3}$ Animal Nutrition Group, Wageningen Institute of Animal Sciences, Marijkeweg 40, 6709 PG Wageningen, the Netherlands, ${ }^{4}$ Rowett Research Institute, Greenburn Road, Bucksburn, Aberdeen AB24 9SB, UK

Modern-day dairy farmers, faced with the need to meet quota targets, require an accurate means of predicting responses in milk constituent output to changes in nutrient availability. Present on-farm support systems are not satisfactory, because they comprise a black box approach to inter-organ amino acid metabolism and so have no basis for responsetype predictions. We have been developing steady state kinetic models of liver and mammary gland amino acid metabolism which we hope will improve the prediction of nutrient supply to and utilization by the lactating mammary gland of dairy cows.

Two models using isotope dilution kinetics to partition metabolic leucine into anabolic and catabolic fates in the liver and the mammary gland of lactating dairy cows have been constructed and solved in the steady state. The models have been used to resolve in vivo stable isotope data obtained from experiments with multicatheterized dairy cows during a constant jugular vein infusion of $\left[{ }^{13} \mathrm{C}\right]$ leucine tracer. The inputs required for model solution are blood flow rate across the tissue, leucine, $\alpha$-ketoisocaproate (KIC) and carbon dioxide concentrations and plateau isotope enrichments in the arterial supply to and the venous drainage from each of the tissue beds, and plateau enrichments for leucine and KIC in the tissue intracellular pool. Using these data and a limited number of assumptions, the models can be solved to calculate the rates of leucine uptake, release, oxidation and transamination, and leucine fluxes representing the synthesis and degradation of constitutive and export proteins. Using the model solutions and appropriate literature values for organ protein mass and leucine content, total (constitutive and export) protein fractional synthesis rates (FSRs) can be estimated for both the liver and the mammary gland.

The in vivo studies were conducted in multicatheterized Holstein-Friesian dairy cows (six liver; three mammary gland) during weeks 20-30 of lactation. Average cow data: body weight $600 \mathrm{~kg}$; dry matter intake $16 \mathrm{~kg} / \mathrm{d} \quad(60: 40$ concentrate:grass silage, $135 \mathrm{~g}$ crude protein $/ \mathrm{kg} \mathrm{DM})$; milk yield $24 \mathrm{~kg} / \mathrm{d}$. Total liver protein FSRs ranged from 23 to $55 \% / \mathrm{d}$, with assumed export protein contributing between 9 and $21 \%$ of total protein synthesis. For the mammary gland, total protein FSRs ranged from 39 to $53 \% / \mathrm{d}$, with measured export protein (milk) contributing $60-88 \%$ of total protein synthesis.

The level of representation adopted means that both models could be applied to other amino acids with similar metabolic fates within the liver and the mammary gland. Linking the models consecutively will allow quantitative description of the effects of liver metabolism on amino acid availability to peripheral tissues and simultaneously quantify the partition of amino acids between the mammary gland and peripheral tissues (muscle) and within the mammary gland between milk protein synthesis and other metabolic fates.

This work was funded by a consortium of MAFF, BBSRC, Milk Development Council, Purina Mills, Inc. and Hendrix Voeders B. V.

Integrated models of grassland and livestock systems to assess the impact of climate change. K. COOPER ${ }^{1}$, D. J. PARSONS ${ }^{1}$, A. C. ARMSTRONG ${ }^{2}$, A. M. MATTHEWS $^{2}$, J. R. TURNPENNY ${ }^{3}$, J. A. CLARK $^{3}$ AND A. J. McARTHUR ${ }^{3}$. ${ }^{1}$ Silsoe Research Institute, Wrest Park, Silsoe, Bedford MK45 4HS, UK, ${ }^{2} A D A S$ Gleadthorpe, Meden Vale, Mansfield, Notts NG20 9PF, UK, ${ }^{3}$ Environmental Science Division, School of Biological Sciences, University of Nottingham, Sutton Bonington Campus, Loughborough, Leics LE12 5RD, UK

This project used mathematical models to assess how climate change could affect grassland-livestock and intensive livestock systems. Different climate change scenarios were used to generate a set of weather data for the year 2050 for three representative regions of 
the UK which were then used with the integrated model. The systems studied were: beef calf, dairy cow, lamb, pig and broiler.

The system models, collectively known as ECCLIPS (Effect of Climate Change on Livestock Production Systems), simulate the effects of climate on livestock through the direct effects of heat, radiation and temperature, modified by buildings when appropriate, and the effects on grass production, which affects the management and productivity of ruminant systems. The system models predict the grass production, and consumption (where relevant) based on SWARD (Dowle \& Armstrong 1990), the growth rate of animals raised for meat (Stranks et al. 1988) and the milk yield of dairy cows (ARC 1980), the frequency of heat stress experienced by the animals (Turnpenny 1997), and the energy inputs required for ventilation of the intensive livestock houses (Cooper \& Parsons 1998).

Each system model contains submodels for feed consumption, leading to heat production and the thermal balance of the animal with its environment. For pigs and broilers there is a model of the thermal balance of controlled-environment buildings, and hence of the artificial climate experienced by the animals. For both types of cattle there is a similar model of naturally-ventilated buildings, that is used throughout the winter months. All three ruminant systems include a grass production model that predicts the yield and quality under grazing and silage harvesting. The main interactions between the models are as follows:

(i) the grass production model provides one of the main inputs to the feeding model, which controls the rate of consumption of grass during grazing and as silage;

(ii) the feeding model sets the level of metabolic heat production for the animal thermal model, which has a feedback effect through the reduction in intake in conditions of high heat stress;

(iii) the building thermal model simulates the microclimate experienced by the housed livestock, and is partly driven by the rate of heat dissipation from the animal thermal model.

The results showed that grassland-livestock enterprises are well capable of adapting to climate change. Heat stress will be an increased risk for intensive livestock, especially broilers, unless there is investment in improved ventilation and cooling systems. Climate change will result in a modest increase in grass production and thus grass-based enterprises are likely to have a small increase in profits. Overall, there is no evidence of change in the relative suitability of the areas considered for the major types of livestock enterprises.

The Ministry of Agriculture, Fisheries and Food is thanked for funding this research.
Agricultural Research Council (1980). The Nutrient Requirements of Ruminant Livestock. Slough: Commonwealth Agricultural Bureaux.

CoOper, K. \& Parsons, D. J. (1998). A thermal balance model for livestock buildings for use in climate change studies. Journal of Agricultural Engineering Research 69, $43-52$.

Dowle, K. \& Armstrong, A.C. (1990). A model for investment appraisal of grassland drainage schemes on farms in the UK. Agricultural Water Management 18, $101-120$.

Stranks, M.H., Cooke, B. C., Fairburn, C. B., Fowler, N. G., Kirby, P.S., McCrackern, K. G., Morgan, C. A., Palmer, F.G. \& Peers, D.G. (1988). Nutrient allowances for growing pigs. Research and Development in Agriculture 5, 71-88.

TURNPENNY, J. (1997). The impact of climate change on the energy balance of UK livestock. PhD thesis, University of Nottingham.

Real time forecasting of winter wheat yield. M. BANNAYAN AND N. M. CROUT. School of Biological Sciences, Environmental Science Division, University of Nottingham, Sutton Bonington Campus, Loughborough, Leics LE12 5RD, UK

Timely and accurate crop yield forecasting at different temporal and spatial scales is becoming important at both national and international levels. Accurate crop yield forecasts would enable improved management decision making by providing timely information. For example, the ability to evaluate weather and crop growth conditions at any time prior to harvest could be useful in evaluating optimum planting date, fertilizer application rates and times, irrigation amounts and timing, and any required pest, weed and disease control programmes.

There have been many attempts to predict crop yield before harvest. The simplest methods are those based on a characteristic index, for example a soil or climate index. There is also interest in using techniques such as remote sensing, regression, Markov chains, and even expert systems to forecast yield. In this study we focus on forecasting using crop simulation models. Our goal was to test if the crop growth models are in a sufficient stage of development to be used in yield forecasting and, if so, to what level of accuracy. Thus the SUCROS (van Keulen et al. 1982) and CERES-WHEAT (Godwin et al. 1990) models, together with a simple weather-based simulation model (unpublished) which we developed at Nottingham, were used to forecast the yield of winter wheat. We shall present results of stochastic forecasting using the sUCROS model.

The sucros model was used for site specific real time crop biomass forecasting. To enable a stochastic forecast to be made, generated weather data were combined with observed data for model updating. The forecast procedure was tested with field data collected at four sites in the UK over two growing seasons. The results showed that across all sites-years, 
the model is able to forecast the final biomass with $4.95 \%, 1.23 \mathrm{tha}^{-1}$ and $0.58 \mathrm{tha}^{-1}$ as mean percentage error, root mean square difference and mean bias error, respectively, at anthesis. The model showed overprediction at any forecast date. There was no significant difference between observed and forecasted biomass for forecasts made at anthesis ( $t$-test, $P=$ $0 \cdot 21)$ or grain milky stage ( $t$-test, $P=0 \cdot 33$ ), although earlier forecasts (before anthesis) did show significant differences $(P<0 \cdot 05)$. Spearman's rank correlation test was used to investigate whether the observed rankings of final biomass between sites and year is correlated with the forecasted ranking. A significant correlation was found for both anthesis $\left(r_{\mathrm{s}}=0.75\right.$, $n=7, \alpha=5 \%)$ and grain milky stage $\left(r_{\mathrm{s}}=0.88\right.$, $n=7, \alpha=5 \%)$. At these two forecast dates, the model accounted for 65 and $82 \%$ of the variation in the observed data, after eliminating data for one of the eight site-years.

Godwin, D., Ritchie, J., Singh, U. \& Hunt, L. (1990). A Users Guide to CERES-WHEAT. Alabama: International Fertilizer Development Center.

van Keulen, H., Penning de Vries, F. W. T. \& Drees, E. M. (1982). A summary model for crop growth. In Simulation of Plant Growth and Crop Production (Eds F. W. T. Penning de Vries \& H.H. Van Laar), p. 87. Wageningen: Pudoc.

Satiety splits feeding behaviour into bouts. B. J. TOLKAMP $^{1}$, D. J. ALLCROFT ${ }^{2}$, E. J. AUSTIN ${ }^{2}$, B. L. NIELSEN ${ }^{1}$ AND I. KYRIAZAKIS ${ }^{1} .{ }^{1}$ Animal Biology Division, SAC, The King's Buildings, Edinburgh EH9 3JG, UK, ${ }^{2}$ BioSS, JCMB, The King's Buildings, Edinburgh EH9 3JZ, UK

Animal behaviour is frequently displayed in bouts. Bout analysis aims at finding a bout criterion, i.e. that time between events that separates intervals within, from intervals between, bouts. Methods used for quantitative bout analysis are log-survivorship (e.g. Slater \& Lester 1982) and log-frequency analysis (e.g. Sibly et al. 1990). Both models assume that the probability of the start of an event (or a bout) is independent of the time since the last event (or bout) and that, therefore, events as well as bouts occur according to Poisson processes, i.e. purely at random. These models are also widely applied in feeding behaviour analysis, where bouts can be meals. However, the satiety concept predicts that after terminating a meal, the animal's feeding motivation will be low. The probability of the animal initiating the next meal is expected to increase with time since the last meal and, therefore, meals are unlikely to be randomly distributed. Results of an experiment, in which the feeding behaviour of 16 cows fed complete silage/concentrate feeds was recorded continuously for 30 days with computerized feeders, were used to test the suitability of existing bout analysis techniques. It is concluded that these techniques give a very poor fit to the observed interval distributions and result in nonsensical meal criteria. A new model is proposed that takes account of the 'shortage' of short intervals between meals that can be observed in our experiment and in a number of published survivorship curves. In contrast with existing models that describe logtransformed frequency distributions of interval lengths, this model describes frequency distributions of log-transformed interval lengths. Compared with existing models, this log-normal model is in better agreement with the biological phenomenon of satiety, it gives a better fit to the observed interval distribution and leads to a more meaningful meal criterion.

The BBSRC, BOCM PAULS, MAFF and SOAEFD are thanked for funding this research.

Sibly, R. M., Nott, H. M. R. \& Fletcher, D. J. (1990). Splitting behaviour into bouts. Animal Behaviour 39, 63-69.

Slater, P. J. \& Lester, N. P. (1982). Minimising errors in splitting behaviour into bouts. Behavior 79, 153-161.

A model to predict the electrical conductivity of bulk soil. M. A. MOJID, D. A. ROSE AND G. C. L. WYSEURE. Department of Agricultural \& Environmental Science, University of Newcastle, Newcastle upon Tyne NE1 7RU, UK

Excess salts in the soil solution adversely affect the growth of plants by osmotic effects, by the toxicity of specific ions, and by degrading the physical condition of soils. Over time, salts may concentrate to such an extent that they render land sterile. Historically, several societies based on irrigated agriculture, for example, ancient Mesopotamia, collapsed due to salinity problems and salt-affected soils currently cover $c .10 \%$ of the total land surface of the earth and one-third of all irrigated land, with $20 \times 10^{6}$ ha being abandoned annually.

Traditionally, soil salinity has been estimated from the electrical conductivity (EC) of the soil solution measured in the laboratory on a disturbed sample of soil and used to compute the amount of leaching water needed to decrease the salinity to acceptable levels. Recently, however, it has become possible to measure the EC of bulk soil continuously and in situ using time-domain reflectometory (Mojid et al.1997). There is thus a need to model the relationship between the EC of bulk soil and that in the soil solution to prescribe the necessary leaching protocols.

Bulk soil consists of three phases: solid, liquid and gas. The EC of soil is governed by its liquid phase only. The most popular model of soil salinity (Rhoades et al. 1989) distinguishes between the water and salt present in the soil in the 'immobile' (fine pores) and 'mobile' (large pores) regions, but relies on empirical relations to partition the pore space 
between these regions. We attempt an alternative approach in which the liquid content of a soil is divided into free solution and the solution in the diffuse double layer (DDL) around the clay particles.

The solution in the DDL contains the exchangeable cations in the soil and so the net ionic concentration in the DDL is higher than that in the free solution. The EC of bulk soil is modelled assuming that the two fractions of the soil solution, through which electrical current flows, act in parallel. The volume of water in the DDL is evaluated from the surface area of the clay and the thickness of the DDL, found from the GouyChapman theory. The surface area of the clay is estimated from its cation-exchange capacity and density of surface charge. A transmission coefficient (analogous to the impedance factor used in the context of solute diffusion) allows for the effect of the tortuous path of current through the soil, and a proportionality constant relates the EC of the solution in the DDL to that in free solution. We obtained over 200 measurements of bulk and solution ECs over a range of salinities and volumetric liquid contents for five different soils. These showed that the transmission coefficient was a linear function of both the volumetric liquid content and the proportion of clay in the solid phase, and it was therefore modelled in terms of these factors. The value of the proportionality constant was optimized at 1.86.

The bulk ECs of five different soils estimated by the model compare well with the measured values, but our results differ in a systematic manner from those calculated using the model of Rhoades et al. (1989).

Mojid, M. A., Wyseure, G. C. L. \& Rose, D. A. (1997). Extension of the measurement range of electrical conductivity by time-domain reflectometry (TDR). Hydrology and Earth System Sciences 1, 175-183.

Rhoades, J. D., Manteghi, N. A., Shouse, P. J. \& Alves, W. J. (1989). Soil electrical conductivity and salinity: new formulations and calculations. Soil Science Society of America Journal 53, 433-439.

Comparison of calibration models for the prediction of forage quality traits using near infrared spectroscopy. S. J. LISTER AND M. S. DHANOA. Institute of Grassland and Environmental Research, Plas Gogerddan, Aberystwyth, Ceredigion SY23 3EB, $U K$

Plant breeders require the ability to screen large numbers of lines or crosses in the early stages of a breeding programme for specific quality traits. However, breeding trials are expensive to conduct and the cost factor may restrict the size of a trial and hence limit the number of samples analysed by conventional laboratory techniques. Near infrared (NIR) spectroscopy has been used widely to measure forage quality and has the ability to screen large numbers of samples rapidly. Simultaneous determination of many parameters is possible once a reliable and robust calibration model has been compiled from a suitable sample population. Models derived using multiple linear regression generally suffer from problems associated with (i) multicollinearity and (ii) the selection of a representative subset of wavelengths. In comparison, 'full spectrum' methods such as principal component regression (PCR) and partial least squares (PLS) regression compress the data into a smaller number of variables which are linear combinations of the original data, and in the latter case are correlated with the reference laboratory data.

A diverse set of samples from grass breeding field trials, primarily perennial ryegrass, Italian ryegrass and hybrid varieties grown under grazing and conservation grassland management systems and from different harvest years, was utilized. The dried and ground samples were scanned using a Foss NIRSystems 6500 (Didcot, Oxon, UK) scanning monochromator. Spectral data was collected at $2 \mathrm{~nm}$ intervals over the range $1100-2500 \mathrm{~nm}$ (700 data points). Laboratory determinations were performed for nitrogen $(\mathrm{N})$, water soluble carbohydrate (WSC) and dry matter digestibility (DMD). Subsets of samples were selected from each of the populations on the basis of their spectral characteristics: from a total of 399, 2792 and 2337, 138, 384 and 1167 were selected for N, DMD and WSC, respectively. These samples were used in the development of models where 'smoothing' treatments (i.e. 1,4,4,1 and 2,6,4,1) (Williams 1987) and standard normal variate and detrend (Barnes et al. 1989) transformations were applied during PCR and PLS regression.

The compositional data for the $\mathrm{N}$ and WSC calibration populations showed normal distributions but a bimodal distribution was found for the DMD population. High correlations were observed between the spectra and the individual quality traits measured. Standard errors of calibration ranged from 0.35 to 0.61 (g/kg DM), $17 \cdot 42$ to 23.04 (g/kg DM) and 10.97 to $16.47(\mathrm{~g} / \mathrm{kg} \mathrm{DM})$ with corresponding $R^{2}$ values of $0 \cdot 99-1 \cdot 00,0 \cdot 89-0.93$ and $0 \cdot 86-0.94$ for $\mathrm{N}$, WSC and DMD respectively, with between 6 and 10 factors being utilized. The predictive ability of the models was assessed initially using cross validation which resulted in standard errors of cross validation ranging from 0.43 to $0.65(\mathrm{~g} / \mathrm{kg} \mathrm{DM}), 17.99$ to $23.05(\mathrm{~g} / \mathrm{kg}$ $\mathrm{DM}$ ) and 11.99 to 16.32 (g/kg DM) for N, WSC and DMD respectively, and indicated good predictive ability. Finally, external validation was performed using an independent set of samples for each population. The standard error of prediction (corrected for bias) ranged from 2.29 to $3.26(\mathrm{~g} / \mathrm{kg}$ DM), $12 \cdot 22$ to $14.98(\mathrm{~g} / \mathrm{kg} \mathrm{DM})$ and $10 \cdot 17$ to $14 \cdot 49$ (g/kg DM) with corresponding $R^{2}$ of $0.67-0.87$, $0.76-0.85$ and $0.68-0.84$ for $\mathrm{N}$, WSC and DMD 
respectively. In addition, mean square prediction error (Theil 1966) was used to assess predictive ability and indicated that bias was the major source of error for the prediction of all forage quality traits.

The performance of PLS calibration models was found to be superior compared to that of the PCR models for all forage quality traits measured. Further, the DMD and WSC models were more precise and robust than those for N. Expansion of the populations to include further seasonal and varietal effects, particularly in the case of $\mathrm{N}$, will aid in the reduction of the errors associated with bias.

Barnes, R. J., Dhanoa, M. S. \& Lister, S. J. (1989). Standard normal variate transformation and de-trending of near-infrared diffuse reflectance spectra. Applied Spectroscopy 43, 772-777.

TheIL, H. (1966). Applied Economic Forecasting. Amsterdam: North Holland Publishing Company.

WiLliams, P. C. (1987). Variables affecting near-infrared reflectance spectroscopic analysis. In Near Infrared Technology in the Agricultural and Food Industries (Eds P. C. Williams \& K. Norris), pp.143-167. St Paul, MN: AACC.

Response of simple neuronal models to stochastic stimulation. D. BROWN AND J. FENG. The Babraham Institute, Babraham, Cambridge CB2 $4 A T, U K$

The integrate-and-fire model underlies the idea that a neurone accumulates charge until a threshold membrane potential is reached, whereupon it fires, and then membrane potential is reset to a level, referred to as the resting potential in many models. The leaky integrator has the additional feature that charge leaks out, so that in the absence of further input, the membrane potential returns to the resting level. In recent years, there has been much controversy about whether simple neuronal models such as these and more complex biophysical models, in response to random synaptic input, can describe well-documented properties of some neuronal systems, such as the neurones of the visual cortex, starting with Softky \& Koch (1993) who asserted that the highly irregular firing of cortical-cells is inconsistent with temporal integration of random excitatory post-synaptic potentials (EPSPs). Recent work of ours has demonstrated how these properties are dependent on the balance between inhibition and excitation in the point process input, and of the distributional form of interarrival time distributions of the inputs, and has clarified some of these arguments.

SoftKy, W. R. \& Косн, C. (1993). The highly irregular firing of cortical cells is inconsistent with temporal integration of random EPSPs. Journal of Neuroscience 13, 334-350.
Evaluating a crop nitrogen simulation model using data from a field experiment with lettuce. J. YANG ${ }^{1}$, G. A. WADSWORTH ${ }^{1}$, D. L. ROWELL ${ }^{1}$ AND I. G. BURNS ${ }^{2}$. ${ }^{1}$ The University of Reading, Department of Soil Science, Whiteknights, PO Box 233, Reading RG6 6DW, UK, ${ }^{2}$ Horticulture Research International, Wellesbourne, Warwick CV35 9EF, UK

Many models of $\mathrm{N}$ dynamics have been built to make a budget for maximizing crop yield and minimizing leaching. The simulation model N_ABLE is of this type (Greenwood et al. 1989, 1996). A field experiment with lettuce was carried out recently to evaluate $\mathrm{N}_{-}$ ABLE. The general findings are as follows. The growth curve of lettuce is an asymmetrical S-shaped curve when the growth period is either 57 or 61 days in every $\mathrm{N}$ treatment. This implies that $\mathrm{N} \_$ABLE, which assumes a J-shaped growth curve (Greenwood et al. 1977), is most reliable in the first three-quarters of the growing period, but the model deviates from the data as harvest maturity approaches. Simulated soil mineral $\mathrm{N}$ in the $0-30 \mathrm{~cm}$ layer corresponded well with the measured values throughout the experiment by setting parameters for the recovery of soil mineral $\mathrm{N}$ (REC) at 0.72 (i.e. $72 \%$ ) and soil $\mathrm{N}$ mineralization rate (NR) at $1 \cdot 1 \mathrm{~kg} \mathrm{ha}^{-1} \mathrm{day}^{-1}$, both higher than default values. This suggests that soil mineral $\mathrm{N}$ is particularly sensitive to REC and NR in the model, and further information on their variability in field experiments is necessary. Comparing three treatments with different ratios of basal and two top dressings of $\mathrm{N}$ fertilizer $\left(\mathrm{N}_{\mathrm{A}}=80 / 50 / 50, \mathrm{~N}_{\mathrm{B}}=180 / 60 / 0\right.$ and $\mathrm{N}_{\mathrm{C}}=70 / 120 / 50 \mathrm{~kg} \mathrm{~N}^{-1}$ ), there was no significant difference in dry matter (DM), but the patterns of soil mineral $\mathrm{N}$ distribution were different during the growing period. Soil mineral $\mathrm{N}$ changed from 72 to $167 \mathrm{~kg} \mathrm{~N} \mathrm{ha}^{-1}$ in $\mathrm{N}_{\mathrm{A}}$, from 107 to $288 \mathrm{~kg} \mathrm{~N} \mathrm{ha}^{-1}$ in $\mathrm{N}_{\mathrm{B}}$ and from 123 to $256 \mathrm{~kg} \mathrm{~N}^{-1}$ in $\mathrm{N}_{\mathrm{C}}$, which indicates that $\mathrm{N}_{\mathrm{A}}$ is the most $\mathrm{N}$-efficient treatment in this study. However, both DM and soil $\mathrm{N}$ data were found to violate normality and equal variance assumptions. After transformation of the data (Royston 1982; SAS 1990), linear regression $y_{\mathrm{s}}=a+b y_{\mathrm{m}}\left(y_{\mathrm{s}}=\right.$ simulated data, $y_{\mathrm{m}}=$ measured data) with a lack of fit test were carried out to test whether the coefficients deviated from $a=0$ and $b=1$, while residual difference between simulated and measured data was tested by $F$-test and $t$-test. The results indicate that there is no robust statistic which can be used to draw a perfect conclusion in model evaluation, but a combination of these methods can provide a satisfactory conclusion.

Greenwood, D. J., Cleaver, T. J., Loquens, S. M. H. \& NiENDORF, K. B. (1977). Relationship between plant weight and growing period for vegetable crops in the United Kingdom. Annals of Botany 41, 987-997.

Greenwood, D. J. \& DraycotT, A. (1989). Experimental validation of an N-response model for widely different crops. Fertiliser Research 18, 153-174. 
Greenwood, D. J., Rahn, C. R., Draycott, A., Vaidyanathan, L. V. \& Paterson, C. (1996). Modelling and measurement of the effects of fertiliser-N and crop residue incorporation on $\mathrm{N}$-dynamics in vegetable cropping. Soil Use and Management 12, 13-24.

Royston, J. P. (1982). An extension of Shapiro and Wilk's
W test for normality to large samples. Applied Statistics 2 , 115-124.

SAS Institute (1990). Econometric Modelling, Simulation and Forecasting. SAS/ETS Software, Applications Guide 2, Version 6, First Edition, pp. 67-98. Cary, NC: SAS Institute. 